\title{
Gait Variability Is Associated with Subclinical Brain Vascular Abnormalities in High-Functioning Older Adults
}

\author{
Caterina Rosano $^{\mathrm{a}} \quad$ Jennifer Brach ${ }^{\mathrm{b}}$ Stephanie Studenskic ${ }^{\mathrm{c}} \quad$ W.T. Longstreth Jr. ${ }^{\mathrm{d}, \mathrm{e}}$ \\ Anne B. Newman ${ }^{a}$ \\ ${ }^{a}$ Department of Epidemiology, Graduate School of Public Health, ${ }^{\mathrm{b}}$ Department of Physical Therapy, \\ School of Health and Rehabilitation Sciences, and ${ }^{\mathrm{C}}$ Division of Geriatric Medicine, Department of Medicine, \\ University of Pittsburgh, Pittsburgh, Pa., and d Department of Neurology, School of Medicine, and e Department of \\ Epidemiology, School of Public Health and Community Medicine, University of Washington, Seattle, Wash., USA
}

\section{Key Words \\ Gait variability $\cdot$ White matter grade $\cdot$ Brain infarcts \\ Community-dwelling older adults}

\begin{abstract}
Background: Gait variability is an index of how much gait parameters, such as step length, change from one step to the next. Gait variability increases with age and in individuals affected by cortical and subcortical neurodegenerative conditions, and it is associated with falls and incident mobility disability. The brain anatomical correlates of gait variability have not been studied in high-functioning communitydwelling older adults. Methods: Gait variability and brain MRIs were assessed in a cohort of 331 men and women (mean age $=78.3$ years) free from stroke, dementia or Parkinson's disease. Gait variability was computed for spatial parameters (step length and step width) and for temporal parameters (stance time). Subclinical brain vascular abnormalities were measured on brain MRIs as infarcts and white matter hyperintensities. Results: Greater variability of step length was associated with greater prevalence of infarcts, including infarcts in the basal ganglia, and with greater white matter hyperintensities severity, independent of age, gender, cognitive function and cardiovascular disease. Weaker
\end{abstract}

\section{KARGER}

Fax +41613061234

E-Mail karger@karger.ch

www.karger.com
(C) 2007 S. Karger AG, Basel

Accessible online at:

www.karger.com/ned associations were found between the other variability measures and the MRI measures. Conclusion: In this group of older adults free from neurodegenerative diseases, a greater variability of step length was associated with greater burden of subclinical brain vascular abnormalities as defined by MRI.

Copyright $\odot 2007$ S. Karger AG, Basel

\section{Introduction}

Gait parameters, such as the step length or the time to swing from one leg to the other, do not remain absolutely uniform but rather fluctuate from one step to the next. The step-to-step variability of gait parameters is usually modest, with changes that are in the order of only a few percent in healthy adults [1]. Recent studies have shown that greater variability in step length, step time and stance time in community-dwelling older adults is associated with risk for falls and risk to develop future mobility disability [2-4]. Thus, greater gait variability is emerging as an indicator of early age-related mobility impairment. However, the underlying mechanisms of variable gait have not been examined systematically in communitydwelling older adults.
Caterina Rosano, MD, MPH

Department of Epidemiology, Graduate School of Public Health University of Pittsburgh

130 N. Bellefield, Room 512, Pittsburgh, PA 15213 (USA)

Tel. +1 412383 1294, Fax +1 412383 1308, E-Mail rosanoc@edc.pitt.edu 
Fig. 1. Simplified diagram of the possible mechanisms controlling gait variability. Some degree of gait variability commonly accompanies gait. Boxes shaded in gray indicate the conditions that may cause increased gait variability and its consequences. PNS = Peripheral nervous system.

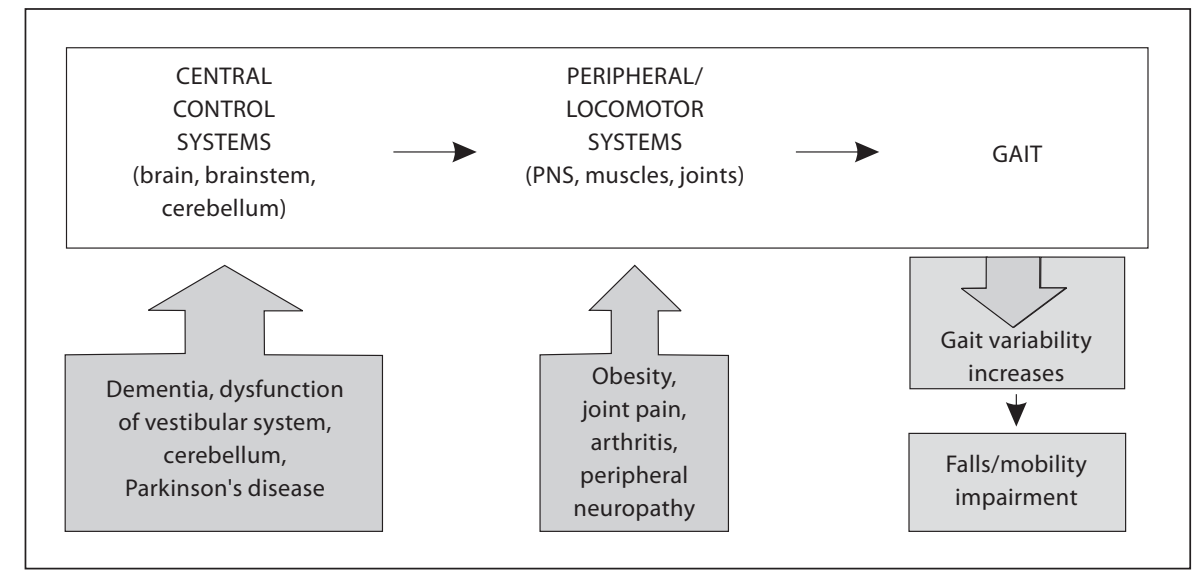

Greater gait variability may indicate underlying impairments of multiple systems [4], including the peripheral and central nervous systems, as well as common nonneurological conditions such as obesity and arthritis. Gait parameters become increasingly variable with increasing age [5] or when walking under challenging conditions [6] or when performing dual tasks $[7,8]$. Increased step length variability and asymmetry in timing also increase in individuals with Alzheimer's disease [9] or known basal ganglia disease, such as Parkinson's disease and Huntington's disease $[10,11]$. Figure 1 illustrates possible mechanisms underlying increased gait variability. When the central systems controlling gait are overloaded (e.g. because of complex demanding environmental conditions, or because of a challenged locomotor system secondary to obesity, arthritis or joint pain) or when the central system itself is impaired (e.g. dementia or Parkinson's disease), variability of gait increases, with subsequent greater gait unsteadiness and greater risk for falls. Since increased gait variability in community-dwelling older adults is associated with mobility impairment, it is important to examine the brain anatomical correlates of gait variability independently of these overloading conditions.

There is recent emerging evidence that impaired mobility in community-dwelling older adults is associated with brain anatomical changes independently of other risk factors or conditions [12-22]. In particular, we have recently shown that among older adults free from stroke or dementia, slower gait speed, smaller steps and longer stance times are strong indicators of greater burden of subclinical brain vascular abnormalities, such as brain infarcts and leukoaraiosis, and that these associations are independent of other conditions that may affect mobility [23]. The goal of the current study is to extend our previ- ous work that examined summary measures of gait and to describe the association between the variability of 3 of these measures (step length, step width and stance time) and subclinical brain vascular abnormalities as defined by MRI in adults who are free from stroke, dementia and Parkinson's disease. We hypothesize that the associations between greater variability of these gait parameters and MRI findings will be independent of other contributors of poor gait, such as obesity or arthritis, and of evidence for cognitive dysfunction and basal ganglion dysfunction.

\section{Methods}

\section{Study Population}

The Cardiovascular Health Study is an ongoing, populationbased, longitudinal study of coronary heart disease and stroke risk in older adults. Community-dwelling older adults were identified from Medicare eligibility lists in 4 clinical centers (Forsyth County, N.C., Sacramento County, Calif., Washington County, Md., and Pittsburgh, Pa., USA) and were recruited if they were age 65 or older, noninstitutionalized, able to give informed consent and expected to remain in the area for 3 years. Individuals who were wheelchair bound in the home or were receiving hospice care, radiation therapy, or chemotherapy for cancer were excluded. The original cohort of 5,201 participants was assembled in 1989-1990 with 687 African-Americans being added in 19921993. The 5,888 participants have had annual clinic examinations through 1998-1999, which also included collection of information for all hospitalizations, a review of medical records, and selected laboratory and clinical evaluations. The gait of 560 participants was evaluated at the Pittsburgh Field Center using the GaitMat II, between 1998 and 1999 [24]. Of these, 389 also received a brain MRI in concurrent years [25]. After excluding those with stroke/TIA $(n=14)$, dementia or Parkinson's disease $(n=35)$ and those with hemiparesis $(\mathrm{n}=9)$ - see assessment below - a total of 331 participants were included in this analysis. 
Fig. 2. Diagram showing the most salient measures of gait for the left foot. Step time: the time to cover 1 step length. Step length: the distance between the heel strike of 1 foot to the heel strike of the opposite foot. Stance time: the time spent with 1 foot on the ground (from heel strike to toe off). Step width (not shown): the distance between the innermost boundaries of 2 consecutive steps.

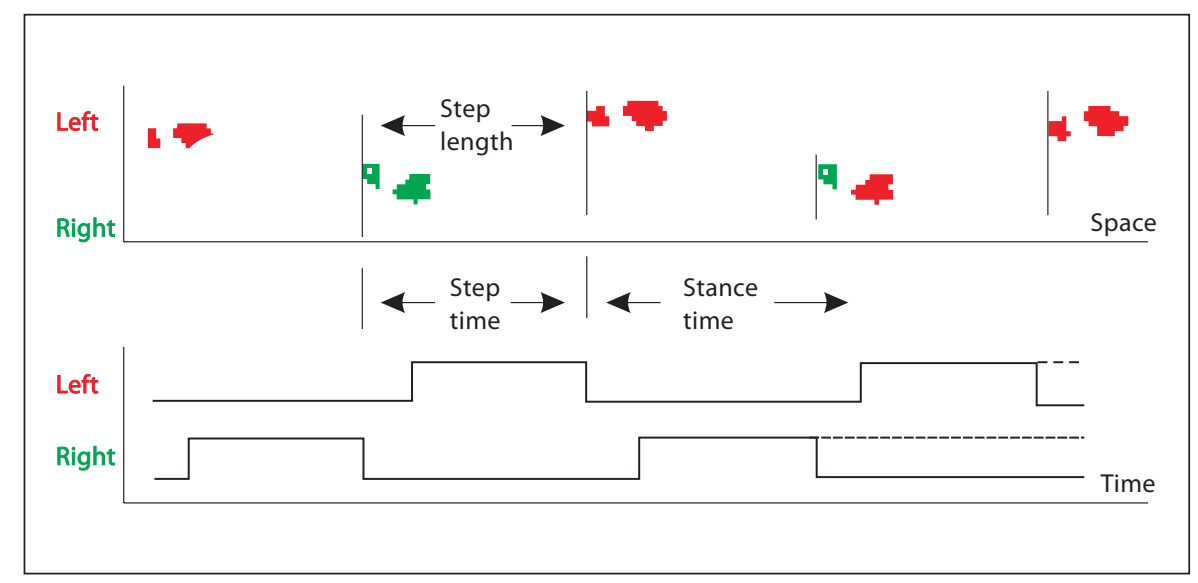

\section{Measurements}

Gait Examination

All participants at the Pittsburgh site who could walk without the assistance of another person and who could follow directions to complete the gait assessment were included in the study. Spatial and temporal measures of gait were determined directly from the footfalls recorded on an instrumented walking surface, the GaitMat II [24]. The GaitMat II consists of a 4-meter-long walkway, on which the subject walks, and a computer system that controls the GaitMat II and analyzes the data. The validity of the GaitMat II measures has been previously tested [24]. For this analysis, we focused on spatial variability in 2 dimensions (i.e. anteroposterior: step length and latero-lateral: step width) and on temporal variability (stance time). We chose these measures also because of their consistent associations with risk for falls and mobility disability [4]. Figure 2 summarizes the definition of these measures. The magnitude of gait variability was measured for right and left foot combined and it was computed as the coefficient of variation, namely the (standard deviation/mean) $\times 100$.

\section{Brain MRI Evaluation}

The brain MRI protocol carried out in 1997-1999 has been described elsewhere [26]. Briefly, sagittal $\mathrm{T}_{1}$-weighted localizer sequences and axial spin-echo spin-density-weighted, spin-echo $\mathrm{T}_{2}$-weighted and $\mathrm{T}_{1}$-weighted images were acquired. All MRI data were interpreted at a central MRI Reading Center using a standardized protocol $[27,28]$. Brain infarcts were defined as an area with a size $\geq 3 \mathrm{~mm}$ and with abnormal signal intensity in a vascular distribution that lacked mass effect and was hyperintense to gray matter on both spin-density and $\mathrm{T}_{2}$-weighted images; a white matter infarct had also to be isodense or hypodense on $\mathrm{T}_{1}$-weighted images. Most of the brain infarcts were located in the basal ganglia. Total burden of white matter hyperintensities (WMH) was recorded according to an atlas of predefined visual standards. The severity of WMH localized in the periventricular or subcortical areas was graded on a 10-point scale, from 0 to 9 , with 9 indicating the greatest extent of increased $\mathrm{WMH}$ on the spin-density images. White matter grade was used as a binary variable (WMH $\geq$ grade 3 , yes/no) with the cutoff point previously used in this cohort of older adults [29].

Gait Variability and Subclinical Brain

Vascular Abnormalities in Older Adults
Evaluation of Neurological and Psychiatric Disorders

Participants with a history of stroke/TIA $(n=14)$, dementia or Parkinson's disease $(n=35)$ or hemiparesis $(n=9)$ prior to the gait assessment and MRI were excluded. Stroke was diagnosed based on self-report at baseline and adjudication thereafter. Dementia was diagnosed based on neuropsychological and neurological examination along with prior annual mental status testing, informant questionnaire for cognitive decline and hospital records, and it has been previously reported [30,31]. Parkinson's disease was diagnosed based on self-report. Basal ganglia function was assessed in the participants of the Pittsburgh cohort by a neurologist using a modified version of the Unified Parkinson's Disease Rating Scale (UPDRS) [32]. Depression was assessed using the Center for Epidemiologic Studies Depression Scale (CES-D) score [33].

\section{Confounders and Covariates}

In addition to demographics (age and gender), we considered the following potential confounders: cognitive function as measured by the modified Mini-Mental State Examination score (3MS), prevalent cardiovascular diseases (CVD), basal ganglia function as measured by UPDRS score and depression as measured by CES-D score. Other conditions that are associated with impaired mobility and that were considered in this analysis were body mass index and self-reported hip/knee pain and joint arthritis. All variables except gender were assessed at the time of brain MRI in 1997-1999. Prevalent CVD included history of myocardial infarction or angina, coronary artery bypass surgery or percutaneous transluminal angioplasty, congestive heart failure, carotid artery surgery, peripheral vascular bypass surgery, angioplasty or intermittent claudication.

\section{Statistical Analysis}

This cross-sectional analysis included 331 eligible participants. Gait variability measures did not follow a normal distribution, with skewness values very high for step width variability and moderately high for the other variability measures. Consistent with the analysis of the parent population of $\mathrm{n}=560$ [24], raw data analyses showed the presence of outliers for step width variability ( $\mathrm{n}=8$ with coefficient of variation $=39.0-214.5$ ). These were actual data and not errors of examination; therefore, 
these values were kept in the analysis. Because of their nonnormal distribution and because we have previously observed a nonlinear association between these measures and falls [2], the gait variability values were also examined as quartiles. $\chi^{2}$ tests of prevalence of MRI findings (brain infarcts $\geq 1$, basal ganglia infarcts $\geq 1, \mathrm{WMH} \geq$ grade 3 ) by quartiles of gait variability measures were examined to detect linear and nonlinear associations. The Sidak correction factor for multiple comparisons ( $\mathrm{n}=$ 3 comparisons for each gait variability measure) of $\mathrm{p}=0.016$ was used to assess significance. The association of gait variability with MRI findings was examined separately for each gait variable in multivariate logistic regression models and confounders/covariates were subsequently added to the model. Those bivariate associations that were significant were further tested in multivariate models with the MRI findings as the dependent variables

\section{Results}

Characteristics of the 331 eligible participants are presented in table 1. Compared to Cardiovascular Health Study participants who received an MRI scan in the years 1997-1999 $(\mathrm{n}=2,317)$, these 331 participants were less likely to have brain infarcts or $\mathrm{WMH} \geq$ grade 3 , more likely to be younger, female, black and more educated $(\mathrm{p}<0.01$ for all). Among the gait variability measures, step width variability was the most variable of all. Exclusion of those with very high step width variability (coefficient of variation $>39.0$ ) still yielded very high average values of coefficient of variation (mean $=15.7, \mathrm{SD}=8.4$; median $=16.7$, interquartile range $=15.6-17.4$ ).

Those with greater variability of step length, step width or stance time were more likely to have any one of the 3 brain MRI findings compared to those with smaller variability (table 2 ). The associations that were significant below the threshold for multiple comparisons correction $(p=0.016)$ were those between step length variability and each of the 3 brain MRI abnormalities, and also those between stance time variability and $\mathrm{WMH} \geq$ grade 3. Stance time variability was also associated with brain infarcts, including basal ganglia infarcts (table 2), although the $p$ values were above the $p=0.016$ threshold for multiple comparisons. Associations remained nonsignificant after log transformation of step width variability or exclusion of those with very high step width variability. Associations with other gait variability measures (e.g. swing time variability, stride length variability, step time variability) were not significant after correction for multiple comparisons.

These bivariate analyses also suggested a nonlinear association between stance time variability and the preva-
Table 1. Population characteristics

Study population

$(\mathrm{n}=331)$

Age at MRI, years

$78.3 \pm 4.0$

Education, years

$15.8 \pm 4.4$

Race (white)

$235(70.6)$

3MS score

$93.5 \pm 5.1$

UPDRS score

$3.8 \pm 4.1$

Cardiovascular risk factors

$70(21.0)$

Prevalent cardiovascular disease

$109(32.9)$

Hypertension

$66(19.9)$

Association

Other factors that are associated with impaired gait

Joint pain

$149(45.0)$

Body mass index

Hip/knee arthritis

$26.4+4.3$

$114(34.5)$

Markers of brain vascular disease

Brain infarcts $\geq 1$

$82(24.8)$

Basal ganglia infarcts $\geq 1$

$60(18.1)$

White matter grade $\geq 3$

$104(31.4)$

Measures of gait variability $(\mathrm{CV})$

Step length variability

Step width variability

$6.3 \pm 3.0$

Stance time variability

$8.9 \pm 19.4$

$4.9 \pm 1.8$

Figures are means \pm SD or numbers of individuals with percentages in parentheses. Brain infarcts: median of the largest diameter: $8.5 \mathrm{~mm}$. Basal ganglia infarcts: median of the largest diameter: $5.0 \mathrm{~mm}$. CV: (standard deviation $/$ mean $) \times 100$.

lence of brain MRI findings. The proportion of individuals with any one of these brain MRI findings was lower in the 2 nd versus the 1 st quartile and then it was consistently greater as stance time variability values increased from the 2 nd to the $3 \mathrm{rd}$ and from the $3 \mathrm{rd}$ to the 4 th quartile. A nonlinear pattern of association was also found between step width variability and $\mathrm{WMH} \geq$ grade 3 , although the differences were not significant.

In multivariate models adjusted for age, gender, 3MS and CVD, a greater step length variability was associated with greater probability of having any one of the 3 brain MRI findings (table 3). Adding UPDRS score or other covariates (e.g.: body mass index, CES-D, pain, osteoarthritis) to the model changed the coefficients by $>8 \%$.

In additional exploratory analyses, the associations with stance time that were significant at $\mathrm{p}<0.05$ but at $p>0.016$, that is above the threshold for multiple comparisons, were tested for significance in multivariate models. Table 4 shows that those with very low (1st quartile) or very high (4th quartile) stance time variability 
Table 2. Prevalence of brain MRI abnormalities by quartiles of gait variability (significance of $\chi^{2}$ tests is reported)

\begin{tabular}{|c|c|c|c|c|c|c|}
\hline & \multicolumn{2}{|c|}{$\begin{array}{l}\text { Brain infarct } \geq 1 \\
(\mathrm{n}=82)\end{array}$} & \multicolumn{2}{|c|}{$\begin{array}{l}\text { Basal ganglia } \\
\text { infarct } \geq 1(n=60)\end{array}$} & \multicolumn{2}{|c|}{$\begin{array}{l}\text { WMH } \geq 3 \\
(\mathrm{n}=104)\end{array}$} \\
\hline & $\mathrm{n}$ & $\%$ & $\mathrm{n}$ & $\%$ & $\mathrm{n}$ & $\%$ \\
\hline \multicolumn{7}{|l|}{ Step length variability } \\
\hline 1st quartile $(\mathrm{CV}<4.23 ; \mathrm{n}=79)$ & 15 & 18.3 & 11 & 18.3 & 21 & 20.2 \\
\hline 2nd quartile (CV $4.23-5.70 ; \mathrm{n}=86)$ & 15 & 18.3 & 12 & 20.0 & 18 & 17.3 \\
\hline 3rd quartile (CV 5.71-7.38; $\mathrm{n}=80)$ & 24 & 29.3 & 14 & 23.3 & 37 & 35.6 \\
\hline 4 th quartile $(\mathrm{CV}>7.38 ; \mathrm{n}=86)$ & 28 & 34.1 & 23 & 38.3 & 28 & 26.9 \\
\hline $\mathrm{p}$ value for $\chi^{2}$ tests & \multicolumn{2}{|c|}{0.006} & \multicolumn{2}{|c|}{0.01} & \multicolumn{2}{|c|}{0.006} \\
\hline \multicolumn{7}{|l|}{ Step width variability } \\
\hline 1st quartile $(\mathrm{CV}<12.6 ; \mathrm{n}=87)$ & 22 & 26.8 & 13 & 21.7 & 29 & 27.9 \\
\hline 2nd quartile (CV 12.6-15.8; $\mathrm{n}=84)$ & 21 & 25.6 & 17 & 28.3 & 21 & 20.2 \\
\hline 3rd quartile (CV $15.8-20.8 ; \mathrm{n}=79)$ & 17 & 20.7 & 11 & 18.3 & 23 & 22.1 \\
\hline 4th quartile $(\mathrm{CV}>20.8 ; \mathrm{n}=81)$ & 22 & 26.8 & 19 & 31.7 & 31 & 29.8 \\
\hline $\mathrm{p}$ value for $\chi^{2}$ tests & \multicolumn{2}{|c|}{0.8} & \multicolumn{2}{|c|}{0.5} & \multicolumn{2}{|c|}{0.7} \\
\hline \multicolumn{7}{|l|}{ Stance time variability } \\
\hline 1st quartile $(\mathrm{CV}<3.6 ; \mathrm{n}=82)$ & 22 & 26.8 & 15 & 25.0 & 21 & 20.2 \\
\hline 2nd quartile (CV 3.6-4.5; $\mathrm{n}=80)$ & 12 & 14.6 & 8 & 13.3 & 20 & 19.2 \\
\hline 3rd quartile (CV $4.6-5.9 ; \mathrm{n}=86)$ & 20 & 24.4 & 15 & 25.0 & 30 & 28.8 \\
\hline 4th quartile $(\mathrm{CV}>5.9 ; \mathrm{n}=83)$ & 28 & 34.1 & 22 & 36.7 & 33 & 31.7 \\
\hline $\mathrm{p}$ value for $\chi^{2}$ tests & \multicolumn{2}{|c|}{0.03} & \multicolumn{2}{|c|}{0.04} & \multicolumn{2}{|c|}{0.01} \\
\hline
\end{tabular}

Table 3. Multivariate logistic regression models

\begin{tabular}{llll}
\hline & \multicolumn{2}{l}{ Odds ratios } & \\
\cline { 2 - 4 } & $\begin{array}{l}\text { brain infarct } \geq 1 \\
(\mathrm{n}=82)\end{array}$ & $\begin{array}{l}\text { basal ganglia } \\
\text { infarct } \geq 1(\mathrm{n}=60)\end{array}$ & $\begin{array}{l}\text { WMH } \geq 3 \\
(\mathrm{n}=104)\end{array}$ \\
\hline $\begin{array}{l}\text { Quartiles of step length variability } \\
\text { 1st quartile (CV <4.23) }\end{array}$ & 1.0 & & 1.0 \\
2nd quartile (CV 4.23-5.70) & $0.9(0.4-2.1)$ & $1.1(0.4-2.7)$ & $0.8(0.4-1.6)$ \\
3rd quartile (CV 5.71-7.38) & $1.9(0.9-4.0)$ & $1.3(0.6-3.2)$ & $2.4(1.2-4.8)$ \\
4th quartile (CV >7.38) & $2.3(1.1-4.9)$ & $2.7(1.1-6.3)$ & $1.4(0.7-2.9)$ \\
\hline
\end{tabular}

Referent: 1st quartile of step length. Odds ratio and 95\% confidence intervals are shown for models adjusted for age, gender, $3 \mathrm{MS}$ score and subclinical CVD.

were $>2$ times more likely to have brain infarcts or basal ganglia infarcts compared to those in the referent category (2nd quartile). Associations with brain infarcts were significant and independent for the 1st and 4th quartiles, while associations with basal ganglia infarcts were significant for the 4 th quartile only. The association between stance time and $\mathrm{WMH} \geq$ grade 3 seemed to follow a similar U-shaped trend, although the associations were not significant for any one of the quartiles.

Gait Variability and Subclinical Brain Vascular Abnormalities in Older Adults

\section{Discussion}

In this group of older adults free from stroke, dementia and other neurological diseases, greater step length variability was significantly associated with subclinical brain infarcts and white matter abnormalities, independent of age or other health-related factors. A secondary, less robust finding of this study was that those with very high or very low variability of stance time were more like-

Neuroepidemiology 2007;29:193-200 
Table 4. Multivariate logistic regression models

\begin{tabular}{|c|c|c|c|}
\hline & \multicolumn{3}{|l|}{ Odds ratios } \\
\hline & $\begin{array}{l}\text { brain infarct } \geq 1 \\
(\mathrm{n}=82)\end{array}$ & $\begin{array}{l}\text { basal ganglia } \\
\text { infarct } \geq 1(n=60)\end{array}$ & $\begin{array}{l}\text { WMH } \geq 3 \\
(\mathrm{n}=104)\end{array}$ \\
\hline \multicolumn{4}{|c|}{ Quartiles of stance time variability } \\
\hline 1st quartile $(\mathrm{CV}<3.6)$ & $2.3(1.1-5.1)$ & $2.3(0.9-5.8)$ & $1.5(0.7-3.4)$ \\
\hline 2nd quartile (CV 3.6-4.5) & 1.0 & 1.0 & 1.0 \\
\hline 3rd quartile (CV 4.6-5.9) & $1.9(0.8-4.2)$ & $2.0(0.8-5.2)$ & $1.63(0.8-3.5)$ \\
\hline 4th quartile $(\mathrm{CV}>5.9)$ & $2.9(1.3-6.3)$ & $3.2(1.3-7.8)$ & $1.96(0.9-4.2)$ \\
\hline
\end{tabular}

Referent: 2nd quartile of stance time. Odds ratio and 95\% confidence intervals are shown for models adjusted for age, gender, $3 \mathrm{MS}$ score and subclinical CVD.

ly to have subclinical brain infarcts, including basal ganglia infarcts.

The association between step length variability and basal ganglia integrity is consistent with our knowledge of the role played by the basal ganglia in controlling mobility. Because of their functional connection with other motor areas, the basal ganglia circuits control motor coordination and rhythmicity [34]. In fact, basal ganglia diseases, such as Parkinson's disease and Huntington's disease, are also associated with disruptions of the rhythmicity of gait and increase in variability [3]. The results of this study and of our previous study [23] suggest that infarcts localized in these regions, albeit small, can impair such regulatory control and impact gait speed and variability. Adults of this study were not known to have Parkinson's disease and were very unlikely to have Huntington's disease, although preclinical Parkinson's disease may have affected them. Nonetheless, in this study, controlling for participants' scores on UPDRS had minimal effects on the associations with step length variability. Perhaps increased step length variability could be considered as a category of subtle mobility disorders related with very early stages of basal ganglia dysfunction, which are predominantly of vascular origin (e.g. subclinical infarcts) and do not seem to be associated with the classical signs of basal ganglion dysfunction.

The association between step length variability and $\mathrm{WMH}$ is also consistent with our previous study on the brain anatomical correlates of gait performance [23]. Signal intensity alterations in the periventricular white matter may reflect changes both in the periventricular ascending thalamocortical and descending corticospinal fibers (e.g. descending motor tracts originating from medial cortical areas) that pass close to the lateral ventricles before enter- ing the internal capsule and therefore interfere with long loop reflexes critical for gait and balance mediated by deep white matter sensory and motor tracts.

The lack of association between step width variability and MRI findings did not seem to be due to the highly skewed distribution of step width variability, as the results did not change after exclusion of those with very high step width variability. Even after excluding these participants, step width remained the most variable gait measure of all, as to indicate that most of these highfunctioning older adults tend to walk with a highly variable step width and that this measure does not carry salient information on underlying brain vascular abnormalities. Perhaps step width is variable for reasons that are more peripheral than central, such as changes in the peripheral nervous system or in muscle strength. Studies with advanced measures of muscle strength and of peripheral nervous system function are needed to explore this mechanism.

The associations between the variability of stance time and the brain MRI measures were less consistent compared to those for step length. Perhaps extreme values of stance time variability correspond to underlying brain abnormalities, while intermediate values are 'normal'. Since these quartiles were chosen for analytical purposes and specifically for this selected population of older adults, they cannot be used as cutoff values for 'normality'. The relatively small number of adults with brain MRI abnormalities included in this study needs to be taken into account as a possible explanation for these weaker effects. This limitation is inherent to the design of this study, since we chose to exclude those with clinical brain MRI abnormalities and focus this study on subclinical brain vascular abnormalities. Studies with larger num- 
bers of adults with brain MRI abnormalities and with wider ranges of gait variability are needed to identify a threshold of clinical utility.

Another possible explanation for the weaker associations between temporal variability and subclinical brain vascular abnormalities is that the brain MRI measures were too crude to detect fine changes in brain structure. Possibly, distinct networks of white matter tracts and of gray matter areas are specific for distinct aspects of gait variability. However, the spatial distribution of the brain networks involved in the central control of gait or of gait variability has not been examined. Our knowledge of the brain anatomical correlates of gait variability is largely limited to studies of individuals with known basal ganglia disease. Future studies of the central determinants of age-related mobility impairment will need to use more sensitive brain imaging techniques such as diffusion tensor imaging and magnetization transfer ratio, to quantify and localize early changes in specific tracts and regions of interest.

\section{Conclusions and Implications}

The increase in variability may be part of a trade-off mechanism that we implement to cope with greater challenges. Such challenges may be external, like walking un- der difficult conditions, or related to age. This compensatory mechanism and the subsequent increase in gait variability may be regulated by the basal ganglia and by their related circuits. If the basal ganglia and their connectivity are impaired, then the implementation of such compensatory mechanisms may be inadequate, and gait variability increases excessively. Such underlying impairment may go unnoticed among older adults free from dementia or stroke and with an overall good mobility. The results of this study indicate that in high-functioning community-dwelling older adults, high step length variability is associated with subclinical infarcts, especially in the basal ganglia, and WMH. Early detection of such brain vascular findings may be clinically relevant because their progression may be modified by controlling cardiovascular risk factors $[35,36]$.

\section{Grants}

The research reported in this article was supported by contracts N01-HC-35129, N01-HC-45133, N01-HC-75150, N01-HC85079 through N01-HC-85086, N01 HC-15103, N01 HC-55222, 1 P30 AG024827 and U01 HL080295 from the National Heart, Lung and Blood Institute, with additional contribution from the National Institute of Neurological Disorders and Stroke. A full list of participating Cardiovascular Health Study investigators and institutions can be found at http://www.chs-nhlbi.org.

\section{References}

1 Gabell A, Nayak USL: The effect of age on variability in gait. J Gerontol 1984;39:662666.

-2 Brach JS, Berlin JE, Van Swearingen JM, Newman AB, Studenski SA: Too much or too little step width variability is associated with a fall history in older persons who walk at or near normal gait speed. J Neuroengineering Rehabil 2005;2:21.

3 Hausdorff JM, Rios DA, Edelberg HK: Gait variability and fall risk in community-living older adults: a 1-year prospective study. Arch Phys Med Rehabil 2001;82:1050-1056.

4 Hausdorff JM: Gait variability: methods, modeling and meaning. J Neuroengineering Rehabil 2005;2:19.

$\checkmark 5$ Grabiner PC, Biswas ST, Grabiner MD: Agerelated changes in spatial and temporal gait variables. Arch Phys Med Rehabil 2001;82: 31-35.
6 Kesler A, Leibovich G, Herman T, Gruendlinger L, Giladi N, Hausdorff JM: Shedding light on walking in the dark: the effects of reduced lighting on the gait of older adults with a higher-level gait disorder and controls. J Neuroengineering Rehabil 2005;2:27.

$>7$ Yogev G, Giladi N, Peretz C, Springer S, Simon ES, Hausdorff JM: Dual tasking, gait rhythmicity, and Parkinson's disease: which aspects of gait are attention demanding? Eur J Neurosci 2005;22:1248-1256.

8 Toulotte CT, Thevenon A, Watelain E, Fabre C: Identification of healthy elderly fallers and non-fallers by gait analysis under dualtask conditions. Clin Rehabil 2006;20:269276.

$>9$ Webster KE, Merory JR, Wittwer JE: Gait variability in community-dwelling adults with Alzheimer disease. Alzheimer Dis Assoc Discord 2006;20:37-40.

10 Baltadjieva R, Giladi N, Gruendlinger L, Peretz C, Hausdorff JM: Marked alterations in the gait timing and rhythmicity of patients with de novo Parkinson's disease. Eur J Neurosci 2006;24:1815-1820.
11 Hausdorff JM, Cudkowicz ME, Firtion R Wei JY, Goldberger AL: Gait variability and basal ganglia disorders: stride-to-stride variations of gait cycle timing in Parkinson's disease and Huntington's disease. Mov Disord 1998;13:428-437.

12 Guttmann CR, Benson R, Warfield SK, Wei $\mathrm{X}$, Anderson MC, Hall CB, Abu-Hasaballah K, Mugler JP 3rd, Wolfson L: White matter abnormalities in mobility-impaired older persons. Neurology 2000;54:1277-1283.

13 Longstreth WT Jr, Manolio TA, Arnold A, Burke GL, Bryan N, Jungreis CA, Enright PL, O'Leary D, Fried L: Clinical correlates of white matter findings on cranial magnetic resonance imaging of 3301 elderly people: the Cardiovascular Health Study. Stroke 1996;27:1274-1282.

14 Camicioli R, Moore MM, Sexton G, Howieson DB, Kaye JA: Age-related brain changes associated with motor function in healthy older people. J Am Geriatr Soc 1999;47:330334. 
15 Longstreth WT Jr, Arnold AM, Beauchamp NJ Jr, Manolio TA, Lefkowitz D, Jungreis C, Hirsch CH, O'Leary DH, Furberg CD: Incidence, manifestations, and predictors of worsening white matter on serial cranial magnetic resonance imaging in the elderly: the Cardiovascular Health Study. Stroke 2005;36:56-61.

-16 Tell GS, Lefkowitz DS, Diehr P, Elster AD: Relationship between balance and abnormalities in cerebral magnetic resonance imaging in older adults. Arch Neurol 1998;55 73-79.

-17 Starr JM, Leaper SA, Murray AD, Lemmon HA, Staff RT, Deary IJ, Whalley LJ: Brain white matter lesions detected by magnetic resonance (correction of resonance) imaging are associated with balance and gait speed. J Neurol Neurosurg Psychiatry 2003;74:9498.

-18 Benson RR, Guttmann CR, Wei X, Warfield SK, Hall C, Schmidt JA, Kikinis R, Wolfson LI: Older people with impaired mobility have specific loci of periventricular abnormality on MRI. Neurology 2002;58:48-55.

-19 Carmelli D, DeCarli C, Swan GE, KellyHayes M, Wolf PA, Reed T, Guralnik JM: The joint effect of apolipoprotein E epsilon 4 and MRI findings on lower-extremity function and decline in cognitive function. J Gerontol A Sci Med Sci 2000;55:M103-M109.

20 Sachdev PS, Wen W, Christensen H, Jorm AF: White matter hyperintensities are related to physical disability and poor motor function. J Neurol Neurosurg Psychiatry 2005;76:362-367.

-21 Baloh RW, Ying SH, Jacobson KM: A longitudinal study of gait and balance dysfunction in normal older people. Arch Neurol 2003;60:835-839.

-22 Rosano C, Kuller LH, Chung H, Arnold AM, Longstreth WT Jr, Newman AB: Subclinical brain magnetic resonance imaging abnormalities predict physical functional decline in high-functioning older adults. J Am Geriatr Soc 2005;53:649-654.
3 Rosano C, Brach J, Longstreth WT Jr, Newman AB: Quantitative measures of gait characteristics indicate prevalence of underlying subclinical structural brain abnormalities in high-functioning older adults. Neuroepidemiology 2006;26:52-60.

24 Brach JS, Bethold R, Craik R, Van Swearingen JM, Newman AB: Gait variability in community-dwelling older adults. J Am Geriatr Soc 2001;49:1646-1650.

25 Lopez OL, Kuller LH, Fitzpatrick A, Ives D, Becker JT, Beauchamp N: Evaluation of dementia in the Cardiovascular Health Cognition Study. Neuroepidemiology 2003;22:112.

26 Yue NC, Arnold AM, Longstreth WT, Elster AD, Jungreis CA, O'Leary DH, Poirier VC, Bryan RN: Sulcal, ventricular, and white matter changes at MR imaging in the aging brain: data from the cardiovascular health study. Radiology 1997;202:33-39.

27 Bryan RN, Wells SW, Miller TJ, Elster AD, Jungreis CA, Poirier VC, Lind BK, Manolio TA: Infarct-like lesions in the brain: prevalence and anatomic characteristics at MR imaging of the elderly - data from the Cardiovascular Health Study. Radiology 1997; 202:47-54.

28 Yue NC, Longstreth WT Jr, Elster AD, Jungreis CA, O'Leary DH, Poirier VC: Clinically serious abnormalities found incidentally at MR imaging of the brain: data from the Cardiovascular Health Study. Radiology 1997; 202:41-46.

29 Kuller LH, Shemanski L, Manolio T, Haan M, Fried L, Bryan N, Burke GL, Tracy R, Bhadelia R: Relationship between ApoE, MRI findings, and cognitive function in the Cardiovascular Health Study. Stroke 1998;29: 388-398.
30 Lopez OL, Jagust WJ, Dulberg C, Becker JT, DeKosky ST, Fitzpatrick A, Breitner J, Lyketsos C, Jones B, Kawas C, Carlson M, Kuller LH: Risk factors for mild cognitive impairment in the Cardiovascular Health Study Cognition Study: part 2. Arch Neurol 2003; 60:1394-1399.

31 Lopez OL, Jagust WJ, DeKosky ST, Becker JT, Fitzpatrick A, Dulberg C, Breitner J, Lyketsos C, Jones B, Kawas C, Carlson M, Kuller LH: Prevalence and classification of mild cognitive impairment in the Cardiovascular Health Study Cognition Study: part 1. Arch Neurol 1998;60:1385-1389.

32 Ballard C, McKeith I, Burn D, Harrison R, O’Brien J, Lowery K, Campbell M, Perry R, Ince P: The UPDRS scale as a means of identifying extrapyramidal signs in patients suffering from dementia with Lewy bodies. Acta Neurol Scand 1997;96:366-371.

-33 Andresen EM, Malmgren JA, Carter WB, Patrick DL: Screening for depression in well older adults: evaluation of a short form of the CES-D (Center for Epidemiologic Studies Depression Scale). Am J Prev Med 1994;10: 77-84.

34 Sano H, Yasoshima Y, Matsushita N, Kaneko T, Kohno K, Pastan I, Kobayashi K: Conditional ablation of striatal neuronal types containing dopamine D2 receptor disturbs coordination of basal ganglia function. J Neurosci 2003;23:9078-9088.

35 Dufouil C, Chalmers J, Coskun O, Besancon V, Bousser MG, Guillon P, MacMahon S, Mazoyer B, Neal B, Woodward M, TzourioMazoyer N, Tzourio C; PROGRESS MRI Substudy Investigators: Effects of blood pressure lowering on cerebral white matter hyperintensities in patients with stroke: the PROGRESS (Perindopril Protection Against Recurrent Stroke Study) Magnetic Resonance Imaging Substudy. Circulation 2005; 112:1644-1650.

-36 Longstreth WT Jr: Brain vascular disease: overt and covert. Stroke 2005;36:20622063. 